in glasshouse tomatoes is common, and preliminary results indicate that foliar sprays containing magnesium are more effective than soil treatments in maintaining normal leaf colour. The plant-breeding programme is concerned mainly with improvements of tomato, cucumber and lettuce.

The investigations on Didymella stem rot of tomato have been continued by the Plant Pathology Department, which is also concerned with powdery mildew of cucumber and wilt disease of carnation as well as mushroom diseases. Some experiments were carried out on chemotherapeutic control of tobacco mosaic virus in the tomato, but it was concluded that this approach is not promising. Although insecticides properly applied should give adequate control of white fly, there are sometimes risks of chemical injury to plants, and for this reason interest has been revived in the method of biological control by wasp parasites. The Entomology Department has begun a series of studies on the effects of environmental factors on the fecundity and development of white fly and on the host/parasite balance. Other investigations by this Department include mushroom pests and the red spider mite. The Crop Protection Department is concerned with the control of mildew of chrysanthemums and aphids on lettuce and with the residual toxicity of certain sprays.

E. C. Humphries

\title{
RADIOLOGICAL HAZARDS TO PATIENTS
}

$\mathrm{A}^{\mathrm{T}}$ $T$ the end of 1956, the Secretary of State for Scotland and the Minister of Health appointed a committee "to review the present practice in diagnostic radiology and the use of radiotherapy in nonmalignant conditions, having regard to the report of the Committee on the Hazards to Man of Nuclear and Allied Radiations".

This committee, under the chairmanship of Lord Adrian, has now produced an interim report (Ministry of Health; Department of Health for Scotland. Radiological Hazards to Patients : Interim Report of the Committee. Pp. 22. London : H.M. Stationery Office, 1959. 1s. $3 d$. net) for the one completed part of its survey, namely, the use of $\mathrm{X}$-rays for mass miniature radiography. The conclusion is drawn that, when properly conducted, examinations by this method make a negligible contribution to the total radiation to which the population is daily exposed. Even on the most pessimistic assumptions, the indefinite continuation of mass miniature radiography at the present rate could add no more than 20 cases of leukæmia to the annual incidence of 2,500 cases in Great Britain ; it is also possible that it would produce no additional cases at all. The gonad doses, which determine the long-range genetical damage, have been found to be even smaller than previously estimated. These very small somatic and genetical risks have to be considered in relation to the undoubtedly large benefits of mass miniature radiography to the health of the population. In 1957, these examinations led to the discovery of nearly 18,000 cases of pulmonary tuberculosis and some 63,000 other abnormalities, which included lung cancer, heart disease and pneumoconiosis. For children and pregnant women, mass miniature radiography is not recommended and should be replaced by normal radiographic procedures with strict limitation of the field to the chest. Some general principles are also given for reducing unnecessary exposure in other forms of diagnostic radiology, in particular fluoroscopy; but the survey of this area is not yet completed.

There is one statement in the introduction (paragraph 10) which may give rise to serious misunderstandings. It is stated, correctly, that a dose of radiation which would double the present mutationrate would cause perceptible damage to the population, and that this dose is estimated to lie between 10 and $100 \mathrm{r}$. per generation. It is also correct to say that at present the dose due to medical radiology does not exceed 3 rads per generation. But it is only for the sake of convenience that genetical damage is usually estimated in terms of the 'doubling dose'. There is no lower threshold to the genetical effects of ionizing radiation, and serious genetical damage will be produced already by doses which are far below the doubling dose. In fact, the report of the Medical Research Council came to the conclusion that, from the point of view of genetical hazards, "the upper limit, which future knowledge may set to the total dose of extra radiation which may be received by the population as a whole, is not likely to be more than twice the dose which is already received from the natural background; the recommended figure may indeed be appreciably lower than this". On this evidence, the danger limit has already been reached or even exceeded in countries where $\mathrm{X}$-rays are used extensively for medical purposes. Against this damage to future generations we must, however, set the benefit to the present one and, although all means must be used to cut down avoidable exposure to radiation, a high amount of exposure will remain unavoidable if the present standards of medical service are to be maintained.

\section{FEEDING THE HUNGRY}

$\mathrm{T}$ HE practical way to wage war on want was the theme of an outstanding address at St. John's College, Annapolis, Maryland, on April 9 by $\mathrm{Mr}$. Gerard Piel, publisher of The Scientific American. Following an account of the way in which science has given man unlimited power and opportunities to change the material conditions of life, Piel shows how it is now possible to bring the elimination of want within the reach not only of the present generation but also of all future generations. Want is no longer a challenge to technology, but to economics and politics; it is a social problem. Thanks principally to the control of mortality, the underprivileged peoples are living longer and feeling well enough to do something about their plight. These aroused people are still extracting the irreplaceable resources of their lands to feed the voracious appetite for raw materials of Western peoples. At present the 